\title{
Electric Arc Surfacing of Defective Plots of Rails in the Area of Electrocontact Welded Joint
}

\author{
Dmitry Nezhivlyak ${ }^{1}$, Andrey Nezhivlyak ${ }^{1}$, and Maria Grechneva ${ }^{2 *}$ \\ ${ }^{1}$ Irkutsk State Transport University, 15, Chernyshevsky St., Irkutsk 664074, Russia \\ ${ }^{2}$ Irkutsk National Research Technical University, 83, Lermontov St., Irkutsk 664074, Russia
}

\begin{abstract}
One of the main causes for the failure of the rails of a continuous joint made by electric contact welding is defects in collapse and wear in the joint zone. We address the usage of electric arc surfacing to repair defective rails. The structure and hardness are studied of the defective areas of rails recovered by electric arc surfacing performed in one and two layers. Static tests and fatigue tests of pilot samples of rails with eliminated defects were carried out. The pilot samples with defects eliminated by electric arc surfacing meet the criteria of static strength to the same degree as the rail samples without surfacing. The surfacing technology that we examined should be adjusted by applying preheating to reduce the cooling rate of metal in the weld zone. Fatigue tests showed a positive effect from surfacing at the wear sites in the welded joint. Performance tests confirm that electric arc surfacing is promising to eliminate defects in the collapse and wear of the rails in the area of the electric contact welded joint.
\end{abstract}

\section{Introduction}

The railways of Russia have over 92 thousand $\mathrm{km}$ of a continuous track, which has about 10 million welded rail joints. The most used is the electric contact welding method $[1,2]$. Areas with reduced metal hardness are formed in the welded joint zone because of improper heat treatment used after welding [3-5]. Considerable deformations and temperatures of the weld zone occur in the surface layers of the rail head. They lead to changes in the structure and properties of the metal and reduce the contact strength and wear resistance of the rails [6-9]. As a result, wrinkling and wear occur, as well as large areas of reduced hardness up to $200 \mathrm{~mm}$ long are formed. This year, 19 thousand wrinkles are registered, which is twice as much as last year. Over the last five years, the fraction of wear and wrinkles in the total number of track defects has increased by $70 \%$. Accordingly, the number of rail breaks in the weld area increases. This determines the relevance of improving the methods of restoring damaged rails and improving their operational properties [10,11]. One of the ways of restoration is electric arc surfacing [12-16]. In order to develop technologies to eliminate crumple and wear of rails in the zone of an electriccontact welded joint, studies were carried out that were performed in one and two layers using electric arc surfacing.

*Corresponding author: $\underline{\text { mgrech@irk.ru }}$ 


\section{Research}

The research used decommissioned due to excessive wear in welded joints rails. The total tonnage of traffic was from 510 to 580 million tons gross. The metal structures in the welded joint zone and in the heat affected zone (HAZ) were analyzed before and after the surfacing, and differences between them were also identified. The hardness of the rail metal was measured at the joint, HAZ of the surfaced metal; its uniform distribution and the absence of jumps were monitored.

Defective specimens cut from the active path were examined. Defective area was processed with grinding wheels. The absence of surface defects was controlled by liquidpenetrant (color) test. Surfacing was performed with PUNAR device with Megatronic FOCUS power supply. The self-shielded cored wire OK Tubrodur 15.43 with a diameter of $1.6 \mathrm{~mm}$ was used. Before surfacing it was heated at a temperature of $400-450^{\circ} \mathrm{C}$. cut from a section of a rail restored by surfacing in one layer; iii) on the longitudinal and the transverse thin sections cut from a section of a rail restored by surfacing in two layers. For macro analysis a stereoscopic microscope MBS-1 was used. Microscopic analysis was performed using an Axiovert 40 MAT optical microscope at $\times 100$ and $\times 500$ magnifications.

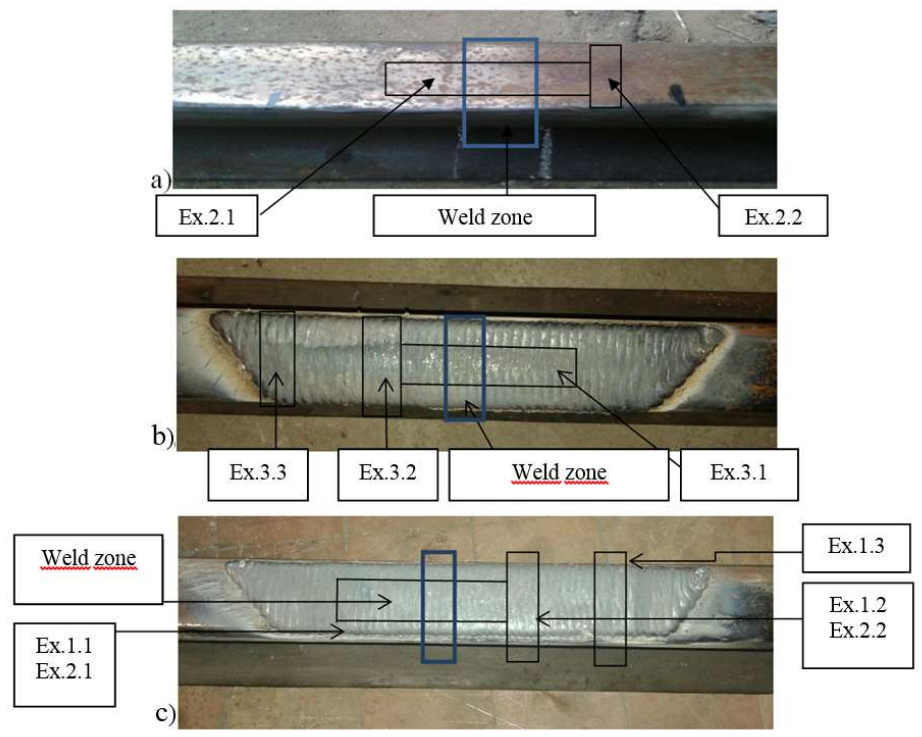

Fig. 1. Cutting scheme of thin sections: a) rail \#1 without surfacing; b) rail \#2 with single-layer surfacing; c) rail \#3 with two-layers surfacing.

Metallographic studies and measurement of the welded joint hardness were carried out on samples cut from three contact-welded rails. Two of them were recovered by surfacing. Fig. 1 presents the scheme of cutting samples for the manufacture of thin sections. The analysis was conducted: i) on the longitudinal thin section cut from the section of the rail without welding; ii) on the longitudinal and transverse thin sections cut from a section of a rail restored by a single-layer surfacing; iii) on the longitudinal and transverse thin sections cut from a section of a rail restored by two-layers surfacing. For macro research a stereoscopic microscope MBS-1 was used. Microscopic examination was performed using an Axiovert 40 MAT optical microscope at $\times 100$ and $\times 500$ magnifications.

Operating cracks were found in the thin section studied (Fig. 2). On the rolling surface of the rail head there are chipped metal, as well as plastic deformation at the rolling surface formed during operation. The metal hardness of the rails was measured on the 
TIMEGROUPINS hardness meter model HVS-10. The pitch was $2.0 \mathrm{~mm}$, the load was 10 kgf (HV10). In the HAZ of the rail joints the distribution of hardness is uniform, no increases or low values were found.

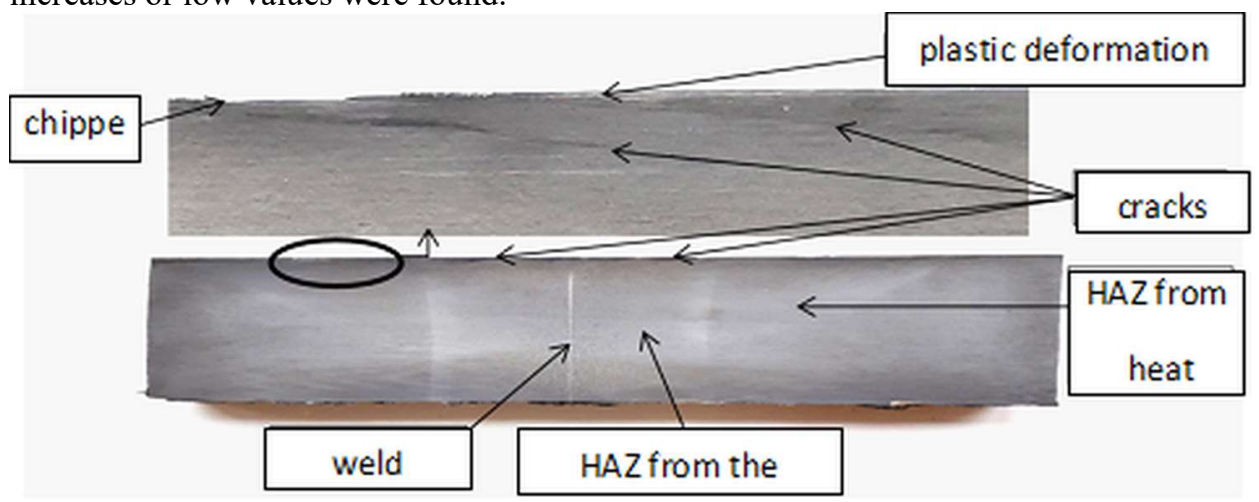

Fig. 2. Macrostructure of a contact-welded joint of rails without surfacing.

Microscopic analysis of a section of a rail that was not restored by surfacing showed that the microstructure of the weld metal and HAZ consists of thin-plate perlite and ferrite. In the weld zone, the rolling surface of the rail head has plastic deformation of the weld metal as well as operational cracks and chips. Similar defects are observed near the weld (Fig. 3). The increased hardness at the rolling surface $349-381 \mathrm{HV}_{10}$ can be explained by the presence of plastic deformation. The hardness at a distance of $10 \mathrm{~mm}$ from the weld is $378-398 \mathrm{HV}_{10}$.

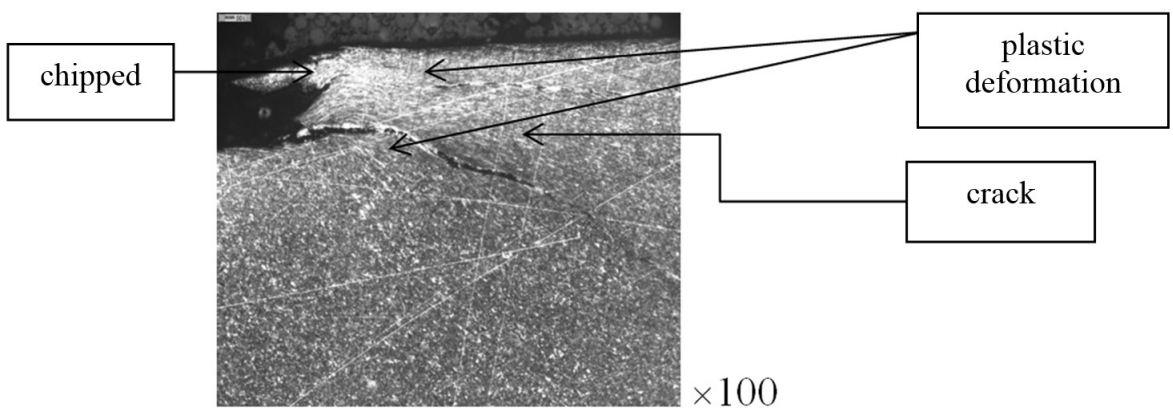

Fig. 3. Defects at the rolling surface of the rail head without surfacing.

The analysis of macrosections of welded joints surfaced in a single layer (Fig. 4) showed the absence of macrodefects in the weld metal and HAZ. The results of the hardness measurement on the longitudinal macrosection of sample 2.1 in Fig. 1 showed that there are no high hardness values in the heat-affected zones from the weld and from the weld metal, but in the weld metal there is an increased hardness value $385 \mathrm{HV}_{10}$. This point of hardness is located at the boundary of fusion of the weld metal with the main one. 


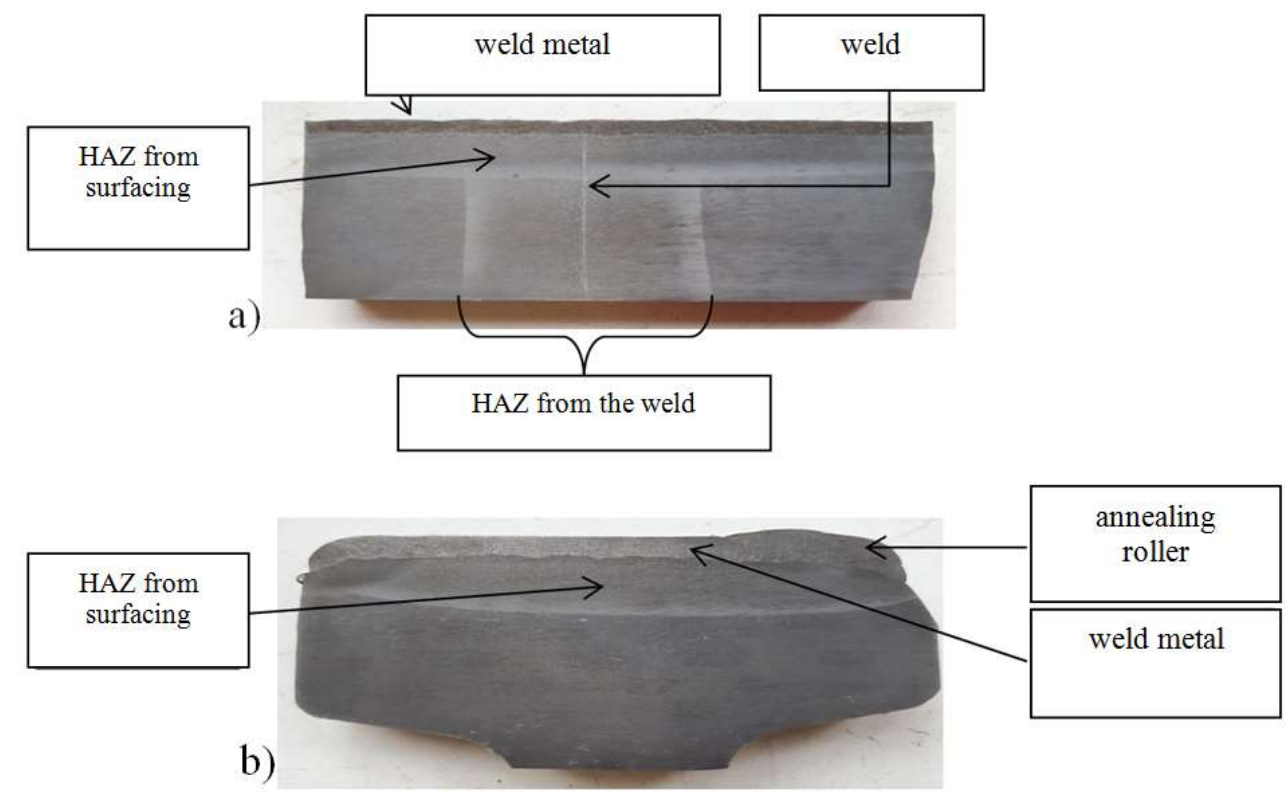

Fig. 4. Macrostructure of a single-layer surfaced rail joint: a) longitudinal thin section; b) transverse thin sections.

Microanalysis of rail thin sections with weld metal showed that the microstructure consisted of fine perlite, ferrite and bainite. The hardness of the weld metal is 343-399 $\mathrm{HV}_{10}$. Small bainite areas with a hardness of 399-401 $\mathrm{HV}_{10}$ are observed in the edge areas of surfacing at the metal fusion boundary under the annealing roller. The structure of the HAZ overheating section in the welding zone consists of thin-plate perlite, ferrite and ferritic mesh. No cracks or other defects in the HAZ were detected.

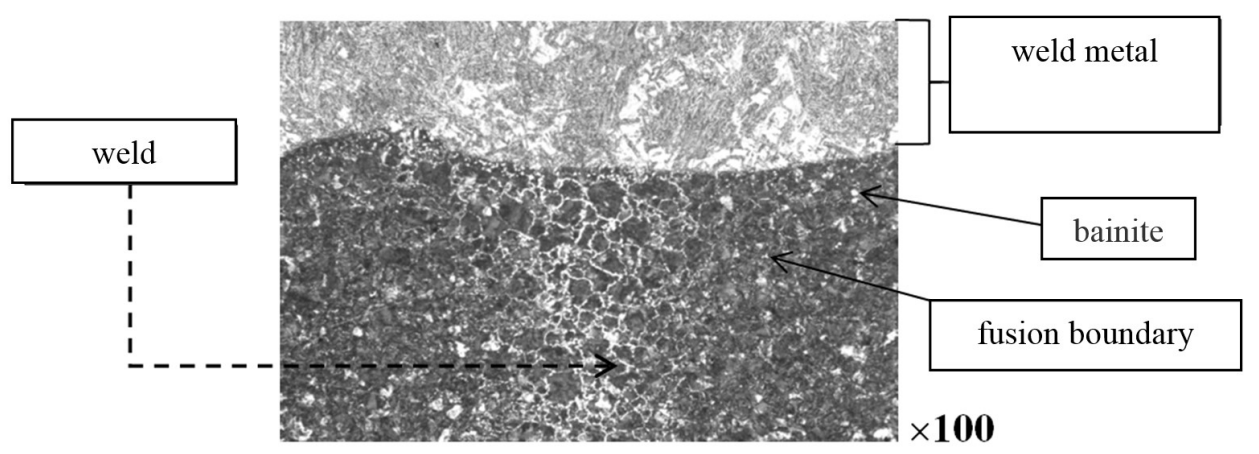

Fig. 5. Fusion boundary of the weld metal in the weld zone (double-layer welding).

Microanalysis of thin sections with a two-layer surfacing (Fig. 5) showed that the structure of the surfaced metal in the lower layer and edge portions of the surfacing consists of bainite. There are areas with a hardness of 380-404 $\mathrm{HV}_{10}$. The structure of the upper layer consists of thin-plate perlite, ferrite and bainite. The hardness is $328-364 \mathrm{HV}_{10}$. Cracks in the weld metal are not detected. No hardening structures were detected in the HAZ. The structure of the HAZ overheating site consists of thin-plate perlite, ferrite and pieces of ferritic network. 
Static tests and fatigue tests of pilot samples of rails with eliminated defects of wrinkling and wear of the rail head in the zone of the welded joint by electric arc surfacing and samples without restoring the head profile were carried out. Static tests were made on a PMM-500 press equipped with means for measuring the load and deflection with plotting a loading diagram. The fatigue tests were carried out on a hydropulser IO-CD $200 \mathrm{PU}$ equipped with measuring tools at an asymmetric cycle with a loading frequency of about $5 \mathrm{~Hz}$.

To assess the effectiveness of the developed technology, operational tests of the rails restored by electric arc surfacing were carried out. There are no defects on the rolling surface of the restored joints. No high hardness values were found, the hardness of the deposited layer is $328 \mathrm{HB}$. Performance tests confirm the viability of this technology to extend the operation of the rails.

\section{Results}

The study of the contact-welded rail template without surfacing showed: i) at the rolling surface of the rail head and in the weld zone there are plastic deformation of the structure of the weld metal, cracks and chips formed during operation; ii) increased hardness at the rolling surface is caused by plastic deformation; iii) quenching structures in the weld zone are not detected.

The structure of the surfaced metal and the HAZ is generally favorable on the rails reconstructed using surfacing. However, there are areas of increased hardness and areas with the bainite structure at the fusion boundaries of the surfaced metal that indicate a high cooling rate in these zones. The surfacing technology needs to be adjusted. It is necessary to apply preheating to reduce the cooling rate of metal in the weld zone.

The pilot samples with defects of wrinkling and wear of the rail head in the weld zone repaired by electric arc surfacing meet the criteria of static strength, such as the breaking load and deflection of the specimen, to the same degree as the rail samples without surfacing. The results of static tests of prototypes are positive.

The fatigue tests showed that the conditional endurance limit of the samples was $\sigma_{0.1}=$ $282 \mathrm{MPa}$ (40 metric ton). For samples of rails without surfacing, this parameter was not possible to measure, because none of these samples passed the tests even at low loads.

\section{Conclusion}

The studies and operational tests have shown that surfacing does not adversely affect the structure or properties of rail metal, weld and HAZ. Static tests of the pilot samples of rails were carried out according to the criteria of static strength. The pilot samples with defects of collapse and wear of the rail head in the weld zone repaired by electric arc surfacing and non-repaired samples are at the same level. Fatigue tests showed a positive effect from surfacing at the wear sites in the welded joint. The conditional endurance limit of rail samples with eliminated wrinkling and wear of the rail head was $\sigma_{0,1}=282 \mathrm{MPa}$ (40 metric toc). The positive result shows the feasibility of using electric arc surfacing to repair the collapse and wear defects of rails in the zone of the electric contact weld.

\section{References}

1. S.I. Kuchuk-Yatsenko, V.I. Shvets, A.V. Didkovsky, E.V. Antipin, and L.M. Kapitanchuk, The Paton Welding J., 9, 2 (2013)

2. S.I. Kuchuk-Yatsenko, A.V. Didkovsky, and V.I. Shvets, The Paton Welding J., 11, 111 
(2008)

3. S.I. Medvedev, A.E. Nezhivlyak, M.V. Grechneva, A.E. Balanovsky, and V.L. Ivakin, Welding International 29:8, 643 (2015)

4. Wen Zefeng, Xiao Guangwen, Xiao Xinbiao, Jin Xuesong, and Zhu Minhao, Eng. Fail Anal. 16, 1221-37 (2009)

5. K. Karimine, K. Uchino, and M. Okamura, Welding International 11:6, 452 (1997)

6. P. Clayton and D. Danks, Wear 135, 369 (1990)

7. H. Desimone and S. Beretta, Intern. J. Fatigue 28, 635 (2006)

8. F.J. Franklin, J.E. Garnham, D.I. Fletcher, C.L. Davis, and A. Kapoor, Wear 265, 1332 (2008)

9. J.E. Garnham and C.L. Davis, Wear 265, 1363 (2008)

10. M.G. Shtayger, A.E. Balanovsky, V.V. Kondratev, A.I. Karlina, and A.S. Govorkov, In: Adv. Engin. Res. Conf. Proc., pp. 360 (2018)

11. A.E. Balanovsky, M.G. Shtayger, V.V. Kondratev, A.I. Karlina, and A.S. Govorkov, J. of Phys.: Conf. Series, 012006 (2018)

12. H. Mansouri and A. Monshi, Sci. Tech. Welding and Joining 9:3, 237 (2004)

13. B.L. Josefson and J.W. Ringsberg, Intern. J. Fatigue 31, 1413 (2009)

14. M. Mousavizade and H. Farhangi, Adv. Materials Res. 83:86, 1262 (2009)

15. H. Aglan, S. Ahmed, K. Prayakarao, and M. Fateh, Engineering 5:11, 837 (2013)

16. J.J. Lewandowski and A.W. Thompson, Metal. Mat. Trans., 17:10, 1769 (1986) 